\title{
Otimização do tempo de estocagem de cavacos de Pinus taeda e Pinus elliottii para a produção de celulose e papel
}

\author{
Optimization of the storage time of Pinus taeda and \\ Pinus elliottii chips for pulp and paper production
}

\author{
Camilla Gabriela Melo Ampessan', Polliana D'Angelo Rios², Martha Andreia Brand ${ }^{3}$, \\ Helena Cristina Vieira ${ }^{1}$ e Daniella Del Castanhel Kniess ${ }^{1}$
}

\begin{abstract}
Resumo
Este estudo teve como objetivo determinar o tempo ideal de estocagem de cavacos de Pinus taeda L. e Pinus elliottii Engelm. em pilhas, para minimização dos problemas derivados da presença de extrativos na madeira destinada à produção de celulose, obtida pelo processo Kraft. Foram utilizadas árvores de Pinus taeda e Pinus elliottii com idade de 22 anos, provenientes de plantios de uma empresa situada em Correia Pinto, Santa Catarina. Foi realizada a análise quantitativa dos extrativos da madeira solúveis em água quente e etanol-tolueno e determinada a variação da temperatura, em diferentes profundidades de pilhas de cavacos de Pinus taeda L. e Pinus elliottii Engelm., durante 8 dias. Houve aumento da temperatura nas pilhas de cavacos, que foi mais intenso nos primeiros quatro dias de estocagem. Não foram encontradas diferenças significativas nos teores médios de extrativos nas profundidades das pilhas de cavacos. A quantidade de extrativos solúveis em etanol-tolueno diminuiu ao longo do tempo de estocagem. O perfil de elevação da temperatura e o decréscimo do teor de extrativos solúveis em etanol-tolueno, para ambas as espécies, indicam que a partir de cinco dias de estocagem os cavacos já apresentaram perda significativa de extrativos, melhorando desta forma sua qualidade para a obtenção de polpa celulósica pelo processo Kraft.
\end{abstract}

Palavras-chave: temperatura, extrativos, tempo de estocagem de cavacos.

\begin{abstract}
This study aimed at determining the optimum storage time of Pinus taeda L. and Pinus elliottii Engelm. chips in piles, for minimizing or eliminating the problems arising from the presence of wood extractives, for the production of Kraft pulp. Trees of Pinus taeda and Pinus elliottii with 22 years old were used, from commercial plantations located in Correia Pinto, Santa Catarina State. During eight days the decay by hot water and ethanol-toluene (1:2) extractives were used to measure the effect of wood chips storage. Temperature variations at different depths of the piles of Pinus taeda L. and Pinus elliottii Engelm. wood chips, were also measured. There was an increase of temperature in the chip piles, which were more intense in the first four days of storage. No significant differences were found in mean extractive contents in the depths of the chip piles. The amount of ethanol-toluene-soluble extractives decreased over storage time. The temperature elevation profile and the decrease in the content of soluble extractives from ethanoltoluene of both species, indicate that from five days of storage onward the chips have had a significant loss of extractives, thus improving their quality to obtain pulp by the Kraft process.
\end{abstract}

Keywords: temperature, extractives, chip storage time.

\section{INTRODUÇÃO}

O setor de celulose e papel nacional tem apresentando, ao longo dos anos, um aumento expressivo e constante, com produção no ano de 2013 de 15,1 milhões de toneladas de celulose e 10,4 milhões de papel (BRACELPA, 2014). Ainda a área ocupada por florestas plantadas, de Eucalyptus e Pinus é de 6.510 .693 ha, onde $73 \%$ corresponde ao Eucalyptus e $27 \%$ de plantio de Pinus (ABRAF, 2011). Diante da busca por produtos de qualidade e preços mais competitivos, o Brasil tem fomen-

\footnotetext{
${ }^{1}$ Mestrando(a) em Engenharia Florestal. UDESC - Universidade do Estado de Santa Catarina. Av. Luiz de Camões, 2090 88520-000 - Lages, SC. E-mail: camillaampessan@hotmail.com

2Professora Titular do Departamento de Engenharia Florestal. UDESC - Universidade do Estado de Santa Catarina / Centro Agroveterinário. Av. Luiz de Camões, 2090 - Conta Dinheiro - 88520-000 - Lages, SC. E-mail: polliana.rios@udesc.br 3Professora Pesquisadora do Departamento de Engenharia Florestal. UDESC - Universidade do Estado de Santa Catarina - Centro Agroveterinário. Av. Luiz de Camões, 2090 - Conta Dinheiro - 88520-000 - Lages, SC. E-mail: martha.brand@udesc.br
} 
tado pesquisas relacionadas à matéria-prima, ao processo e ao produto final, que visam aprimorar conhecimentos devido ao crescente interesse econômico envolvido.

A determinação do tempo ideal de estocagem da madeira utilizada para a produção de papel dentro da indústria pode contribuir com essa busca pelo aumento da qualidade, tanto da matéria-prima, como do processo e em última análise do produto final.

O tempo de estocagem da madeira é determinado pela demanda de matéria-prima e logística. A madeira geralmente é estocada na forma de toras que depois são processadas em cavacos, que são armazenados no pátio da empresa até a entrada no processo produtivo.

Na região serrana sul de Santa Catarina, onde este estudo foi desenvolvido, as indústrias de celulose e papel estocam os cavacos de madeira no pátio por períodos de até 8 dias, tempo este, considerado suficiente para que parte dos compostos voláteis presentes na madeira sejam liberados. Segundo Sjöström e Alén (1998), estes compostos voláteis são os chamados extrativos, que embora se apresentem em quantidades pequenas, podem exercer influência negativa durante o processo de obtenção da celulose e de fabricação de papel.

Os extrativos lipofílicos são materiais extraídos da madeira com solventes orgânicos tais como etanol, acetona ou diclorometano. Os extrativos não polares, comumente chamados de "pitch" ou resinas, são compostos principalmente de ácidos graxos, ácidos resinosos, ésteres de ácidos graxos (por exemplo, ésteres de estéril, ceras, triglicerídeos), e compostos neutros exemplificados por álcoois graxos e esteróis (SITHOLE, 1992). Esses extrativos são compostos hidrofóbicos de baixo peso molecular, e as várias classes de extrativos têm comportamento químico diferente durante a produção da polpa. Alguns dos ésteres são hidrolisados durante a estocagem (HARDELL; NILVEBRANT, 1999). A maioria destes ésteres se mantém inalterados durante o processo de polpação mecânica (HARDELL; NILVEBRANT, 1999). É difícil remover os extrativos lipofílicos durante o processamento ácido e neutro de madeira. No entanto, durante os processos alcalinos, tais como o cozimento Kraft, os ésteres de glicerol são completamente saponificados, e os ácidos graxos e resinas são facilmente dissolvidos como sabões, embora pequenas quantidades permaneçam na polpa. Esteróis, ésteres de esteróis, algumas ceras não são removidos sob as condições alcalinas de processos kraft e, por conseguinte causam problemas na indústria de celulose e papel (GUTIÉRREZ et al, 1999).

Os extrativos quando presentes durante o cozimento geram subprodutos, como o sabão, também designado de "pitch", aumentando o custo de manutenção e prejudicando a operação dos equipamentos, já que resulta em incrustações destes. Os principais constituintes químicos dos extrativos da madeira, responsáveis pelo aparecimento do pitch nas fábricas de celulose são de origem lipofílica (GUTIÉRREZ et al., 1998; SILVESTRE et al., 2005).

Assim a presença de extrativos aumenta o consumo de reagentes, inibe a reação de deslignificação, reduz a qualidade da polpa celulósica e dificulta a recuperação do licor de cozimento (FENGEL; WEGENER, 1983; SENAI/IPT, 1988; SARTO; SANSIGOLO, 2010).

No entanto, Silvério et al. (2008) relatam que a quantidade e composição dos extrativos na madeira podem mudar consideravelmente, dependendo dos procedimentos que antecedem o processo de obtenção da celulose, como a época de colheita, a forma de transporte e a estocagem da madeira. Bittencourt et al. (2006) citam ainda, que também podem alterar de acordo com a temperatura interna e tamanho das pilhas de cavacos, durante a estocagem.

Durante o processo de estocagem da madeira, ocorrem alterações na sua composição química em função da temperatura e umidade do ar. Sendo assim, a fração resinosa da madeira é a que sofre uma ação de degradação mais rápida e intensa com a estocagem. Desse modo, nos processos de polpação, a estocagem produz um efeito benéfico, pois a redução quantitativa ou a alteração dos extrativos diminui a ocorrência de "pitch" na polpa resultante. Contudo, quando se cogita a recuperação dos subprodutos durante o processo de polpação (Kraft), como o tall-oil e terebintina, a estocagem prolongada resulta em perdas consideráveis (SENAI/IPT, 1988).

Devido à importância da estocagem na redução da quantidade de extrativos presentes na madeira, este estudo teve como objetivo determinar o tempo ideal de estocagem de cavacos de Pinus taeda L. e Pinus elliottii Engelm. em pilhas, para minimização dos problemas derivados da presença de extrativos na madeira destinada à produção de polpa Kraft. 


\section{MATERIAL E MÉTODOS}

Para atingir o objetivo definido neste trabalho foi realizada a análise quantitativa dos extrativos presentes na madeira e determinada a variação da temperatura em pilhas de cavacos de Pinus taeda L. e Pinus elliottii Engelm. de acordo com o tempo de estocagem e a profundidade da pilha.

Foram utilizadas árvores de Pinus taeda e Pinus elliottii em idade comercial de corte de 22 anos, provenientes de plantios da empresa Klabin S.A., situada em Correia Pinto, Santa Catarina. A área de estudo está sob influência do clima Cfb segundo a classificação de Köeppen, clima subtropical, com temperatura média anual de $16^{\circ} \mathrm{C}$ e mínima de $2^{\circ} \mathrm{C}$.

\section{Pilha de Cavacos}

As toras de Pinus taeda e Pinus elliottii foram estocadas no pátio da empresa. A madeira de Pinus taeda ficou estocada por 60 dias, e o Pinus elliottii por 30 dias. Após este período, as toras foram para um descascador tipo tambor e posteriormente, processadas em um picador para obtenção dos cavacos.

No pátio da indústria, duas pilhas de cavacos foram formadas, uma para cada espécie. O tamanho e formato das pilhas não foram analisados neste trabalho, sendo avaliadas no experimento pilhas com as mesmas dimensões (altura e formato) que são usualmente utilizadas para a estocagem dos cavacos na indústria. As pilhas tiveram 3 metros de altura e 5 metros de largura. O período máximo de estocagem dos cavacos foi de 7 dias, com uma análise do material recém produzido, no dia 1, no momento da montagem das pilhas.

\section{Amostragem}

Com a finalidade de determinar a temperatura e de coletar as amostras para análise química, de modo uniformizado, nos oito dias de análise, definiu-se 3 perfis e 4 profundidades $(0,6 ; 1,5 ; 2,0$; e 3,0 metros) para cada pilha de cavaco das espécies de Pinus taeda e Pinus elliottii. (Figura 1). A temperatura da pilha foi medida com Termopar PT 100 e em todos os dias foram feitas coletas de cavacos para a realização das análises químicas.

No primeiro dia de analise, os dados representam as condições (quantidade de extrativos e temperatura) do material recém produzido, no momento da montagem das pilhas, portanto sem tempo de estocagem (zero dias de estocagem).

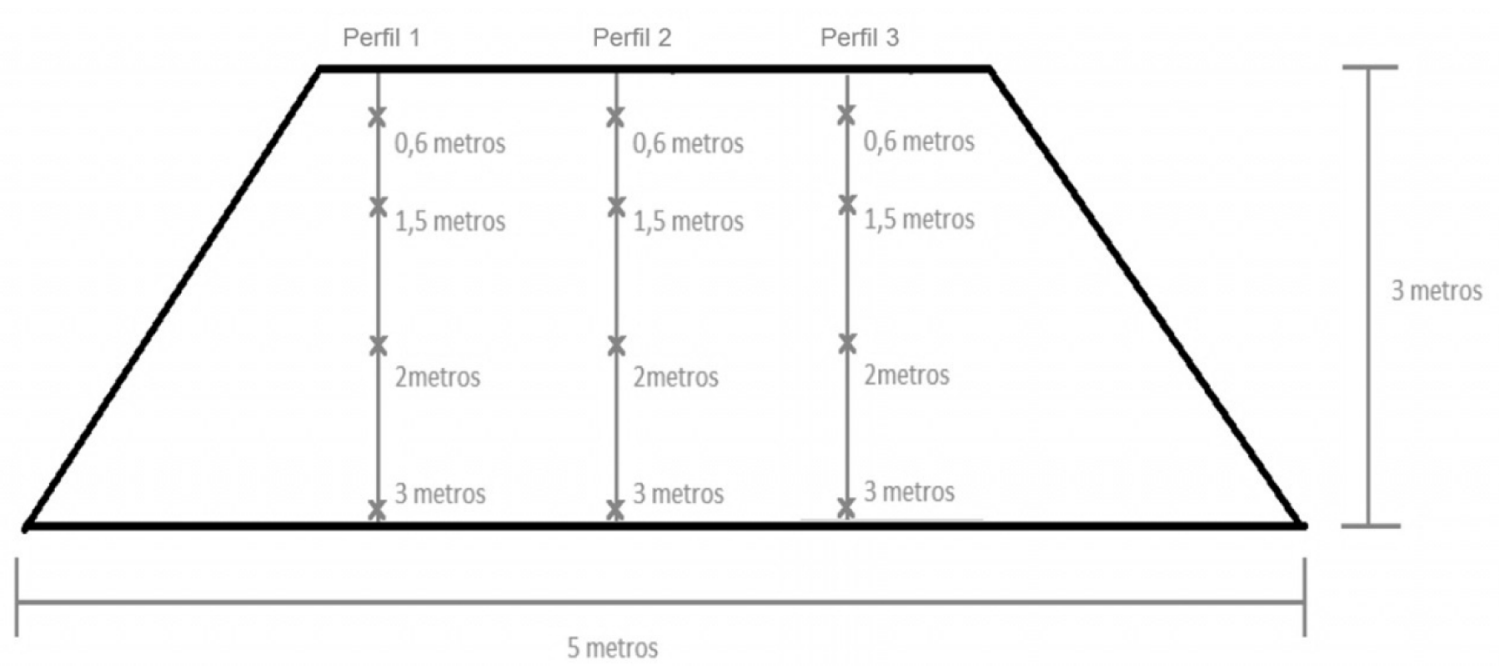

Figura 1. Pontos de coleta dos cavacos e medição de temperatura nas pilhas de cavacos.

Figure 1. Collection points of chips and temperature measurement in chip piles.

\section{Análise Química}

Os constituintes da madeira solúveis em água são principalmente alguns sais ou minerais inorgânicos, açúcares e polissacarídeos. Os compostos solúveis em solventes orgânicos pertencem às classes dos ácidos e ésteres graxos, álcoois de cadeia longa, esteróides, compostos fenólicos e glicosídeos (SUN; TOMKINSON, 2003; MORAIS et al., 2005). 
Mais especificamente, os extrativos da madeira solubilizados pelo diclorometano são as ceras, gorduras, resinas, fitosteróis e hidrocarbonetos não-voláteis. Já a mistura etanol:tolueno (1:2, v/v) extrai da madeira, além dos compostos solúveis em diclorometano, outros compostos insolúveis, como carboidratos de baixa massa molecular, sais e outras substâncias solúveis em água (MORAIS et al., 2005).

Silvério et al (2006), que analisaram diferentes metodologias de extração e determinação do teor de extrativos em madeiras de eucalipto, chegaram a conclusão que a acetona e a mistura tolueno-etanol foram os solventes mais eficientes para a determinação do teor de extrativos totais em todas as espécies estudadas. Além disso, nenhuma diferença significativa foi verificada entre as porcentagens de compostos lipofílicos dos extratos obtidos em acetona ou tolueno-etanol e dos obtidos com as extrações diretas em diclorometano e clorofórmio na maioria das amostras.

Portanto, para este estudo foi determinada como metodologia a determinação dos extrativos através da solubilização da madeira em água quente e álcool tolueno. Para tanto, os cavacos de ambas as espécies foram processados em um moinho tipo Wiley para obtenção de serragem e posteriormente foram classificadas em peneira granulométrica onde as frações de interesse passaram na peneira de 40 mesh e ficaram retidas na de 60 mesh. O material peneirado permaneceu em ambiente climatizado, com condições controladas de umidade $(65 \pm 3 \%)$ e temperatura $\left(20 \pm 2^{\circ} \mathrm{C}\right)$ até massa constante.

Os cavacos coletados em cada profundidade dos 3 perfis (P1, P2 e P3) foram misturados de modo que cada profundidade $(0,6 ; 1,5 ; 2,0$ e 3,0 m) teve uma amostra para cada pilha de cavaco (Pinus taeda e Pinus elliottii). Para cada análise química foram feitas 4 repetições para cada amostra (profundidade) e determinada a solubilidade da madeira em água quente, através da Norma NBR 14577 (ABNT, 2000) e a solubilidade da madeira em etanol-tolueno através da Norma NBR 14853 (ABNT, 2002).

\section{Análise estatística}

Os dados foram analisados por meio do programa de análise estatística SISVAR 4.3. As diferentes profundidades nas pilhas de cavacos foram submetidas à análise de variância, sendo as médias comparadas pelo teste de Scott-Knott a 5\% de probabilidade de erro.

Para os dias de estocagem, primeiramente, realizou-se o teste F para identificação da significância dos tratamentos e da interação. Como a variável dia é quantitativa, foi realizada análise de regressão. No entanto, para as variáveis que não apresentaram equações significativas ou que tiveram coeficiente de determinação $\left(\mathrm{R}^{2}\right)$ baixo procedeu-se o teste Scott-knott $(\mathrm{P}<0,05)$ de comparação de médias.

\section{RESULTADOS E DISCUSSÃO}

\section{Variação da temperatura das pilhas de cavaco}

Na Figura 2 são apresentados os valores médios da temperatura nas pilhas de cavacos de Pinus taeda e de Pinus elliottii, durante os 8 dias de análise, e nas 4 diferentes profundidades e a temperatura do ar.

Para ambas as espécies, as temperaturas foram superiores a do ar, aumentando até o terceiro dia (Pinus taeda) e quarto dia (Pinus elliottii), seguida de redução gradativa até o sétimo dia de estocagem. De uma maneira geral, nos quatro primeiros dias houve um aumento da temperatura, independente da temperatura do ambiente o que foi também foi observado por Rupar e Sanati (2005).

Para as maiores profundidades constatou-se que houve um acréscimo de temperatura não ocorrendo diferenças maiores que $3^{\circ} \mathrm{C}$ entre as profundidades nos 7 dias de estocagem. $\mathrm{O}$ pico máximo de temperatura durante a estocagem foi de $34,3^{\circ} \mathrm{C}$ no terceiro dia para Pinus taeda e de $36,9^{\circ} \mathrm{C}$ no quarto dia para Pinus elliottii.

Uma vez que a madeira é transformada em cavacos e empilhada, vários processos ocorrem, começando com a respiração das células vegetais e atividade microbiana, seguidos por outras transformações físicas e químicas (JIRJIS, 2005). Estes processos resultam na liberação de calor.

Noll et al. (2010) segure que as comunidades bacterianas e fungicas são as principais responsáveis pelos processos exotérmicos que ocorrem no interior de uma pilha de madeira sob estocagem, fato este que promove o aumento da temperatura. 

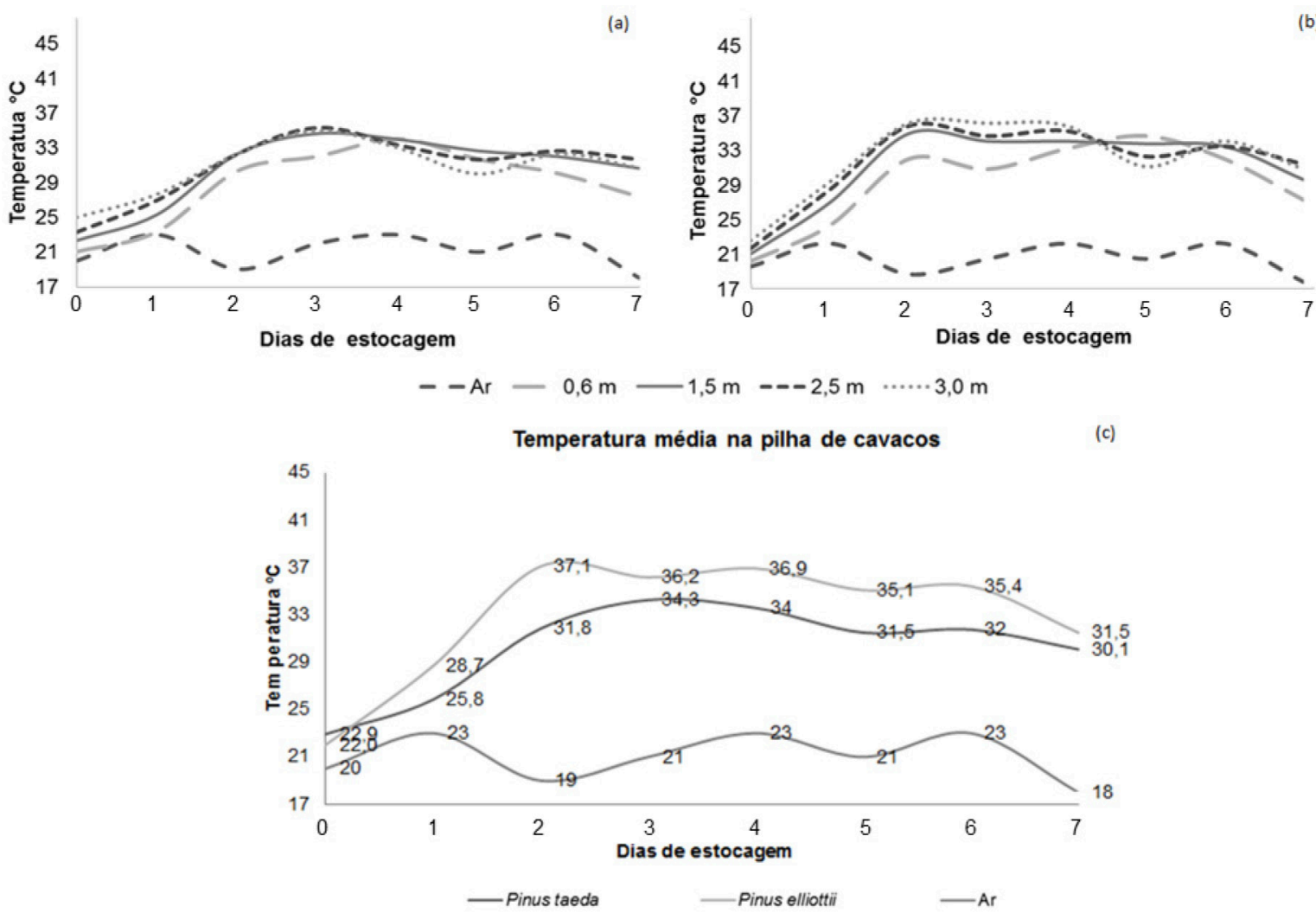

Figura 2. Variação da temperatura nos diferentes pontos de coleta das pilhas de cavaco de Pinus taeda (a) e Pinus elliottii (b), em função do tempo de estocagem. (c) Variação média da temperatura interna de pilhas de cavacos de Pinus taeda, Pinus elliottii e da temperatura ambiente em função do tempo de estocagem.

Figure 2. Temperature variation in the different collection points in the stacks of chips of Pinus taeda (a) and Pinus elliottii (b) related to storage time. (c) Mean change of the internal temperature of piles of Pinus taeda and Pinus elliottii chips, and ambient temperature related to storage time.

Estes processos exotérmicos são derivados das atividades metabólicas dos microrganismos. A atividade microbiana e o aumento da temperatura, de forma conjunta, alteram a composição química dos extrativos da madeira e determinam a sua perda por volatilização.

Barontini et al. (2014) avaliando os efeitos do tempo de estocagem sobre cavacos de biomassa derivada da copa e do tronco de árvores de Populus $x$ canadensis M., na Itália, por um período de seis meses observou que as alterações de temperatura foram mais significantes na primeira semana de estocagem. Nos primeiros dias as temperaturas das pilhas aumentaram significativamente, diminuindo ao longo do tempo e estabilizado por volta do quarto mês de armazenamento.

Noll et al. (2010) também concluíram que a temperatura no interior da pilha aumenta dentro dos primeiros 11 dias após o seu empilhamento, com média de $44^{\circ} \mathrm{C}$ e máximo de $55^{\circ} \mathrm{C}$ no centro da pilha. Depois disso, a temperatura diminuiu continuamente até atingir a temperatura ambiente.

Com relação às variações observadas dentro da pilha, em relação à profundidade de coleta, Barontini et al. (2014) observou o inverso ao que foi observado neste estudo, constatando que houve uma clara diferença entre as camadas da pilha, onde as camadas mais profundas apresentaram temperaturas próximas da temperatura ambiente ao longo de todo o período de armazenamento, e as camadas superiores tiveram maior aquecimento.

O aumento da temperatura em pilhas de cavacos é motivo de atenção devido a possíveis alterações nos rendimentos em celulose, quando em maiores períodos de estocagem os extrativos passam a ser consumidos por agentes degradadores que com suas reações metabólicas liberam energia em forma de calor, aumentando assim a temperatura da pilha (SCHMIDT, 1969).

Para ambas as espécies, nos primeiros quatro dias ocorreram as alterações mais significativas de temperatura, e que contribui para as alterações nos extrativos da madeira em termos de quantidade total mobilizada. Portanto, em períodos mais reduzidos de estocagem, até uma semana, o aumento da temperatura é benéfico para a preparação dos cavacos para polpação. Isso porque a atividade microbiana contribuirá para o consumo de algumas categorias de extrativos (açúcares simples) e pelo aumento da temperatura que favorecerá também a volatilização de outros componentes extrativos. 
No entanto, em períodos maiores de estocagem a degradação biológica promove da alteração da composição química da parede celular o que afetará o rendimento da polpação, tornando a estocagem prejudicial ao processo.

\section{Variação dos extrativos da madeira na profundidade da pilha}

Os resultados, expressos em porcentagem, da análise química da madeira de Pinus taeda e de Pinus elliottii em água quente e solvente orgânico etanol-tolueno em diferentes profundidades, sem considerar o tempo de estocagem, são apresentados na Figura 3.
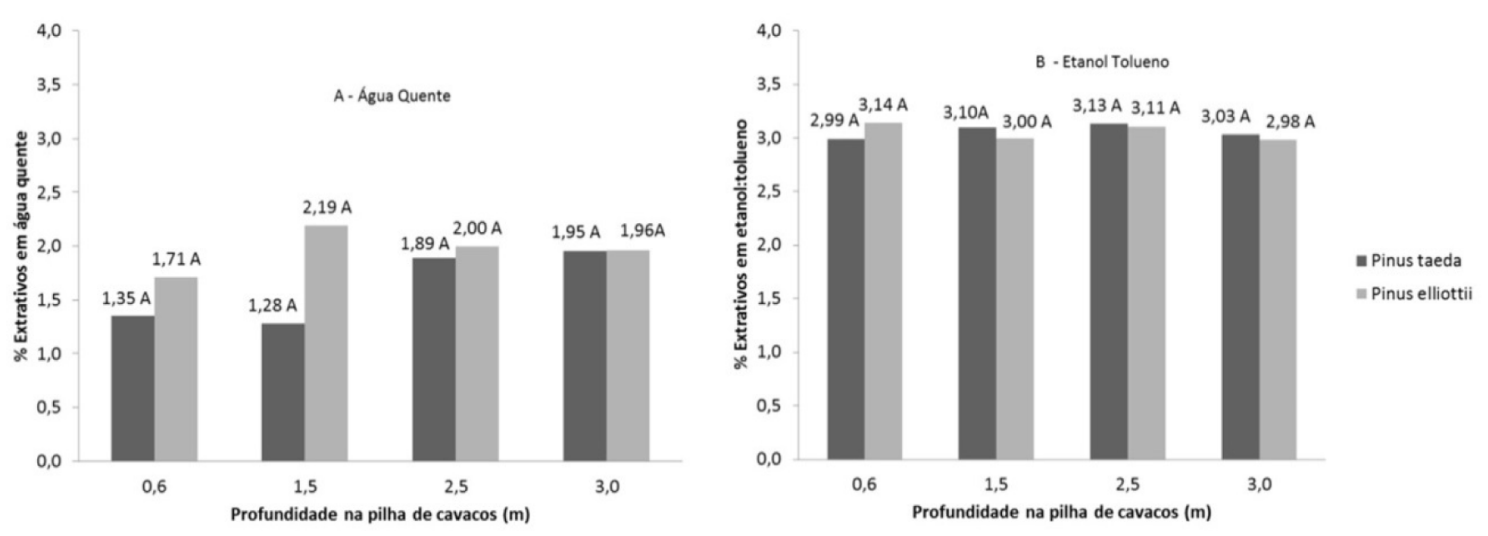

Nota: Os valores médios seguidos da mesma letra não diferem entre si pelo teste de Scott-Knott a 5\% de probabilidade. Note: mean values followed by the same letter do not differ by the Scott-Knott test at $5 \%$ probability.

Figura 3. Porcentagem de extrativos solubilizados em água quente $(A)$ e etanol-tolueno (B) em diferentes profundidades da pilha de cavacos de Pinus taeda e de Pinus elliottii.

Figure 3. Percentage of extractives solubilized in hot water $(A)$ toluene and ethanol $(B)$ at different depths of Pinus taeda and Pinus elliottii chip piles.

Os resultados da análise química para a solubilidade da madeira de Pinus taeda em água quente (A) em diferentes profundidades, apresentou valores médios de 1,28 a 1,95\%. Para o Pinus elliottii os valores médios foram de 1,71 a 2,19\%. Para ambas as espécies, estatisticamente as profundidades não diferiram entre si, de acordo com o teste de Scott-Knott.

Para a solubilidade da madeira em etanol-tolueno, os resultados obtidos para as duas espécies foram similares, apresentando valores médios de 2,99 a 3,13\% (Pinus taeda) e de 3,00 a 3,13\% (Pinus elliottii) também não apresentando diferença estatística significativa entre as profundidades analisadas.

Ressalta-se que a dimensão da pilha experimental foi a mesma que a utilizada pela empresa. Assim, de acordo com os resultados apresentados, a quantidade de extrativos não variou em função da profundidade em que o cavaco estava localizado na pilha. Portanto, o tamanho da pilha é adequado à estocagem dos cavacos para o processo, não influenciando na variação da qualidade dos mesmos em termos de quantidade de extrativos.

\section{Variação dos extrativos da madeira durante a estocagem}

A Figura 4 demonstra os gráficos da análise de regressão entre o teor de extrativos (solúveis em água quente e solvente orgânico) e os dias de estocagem para Pinus taeda e Pinus elliottii.

De acordo com os gráficos, avaliando as duas espécies estudadas, percebe-se diferenças entre as mesmas na solubilidade em água quente e etanol-tolueno. Muñiz (1993) encontrou valores médios de 3,56\% de extrativos solúveis em água quente e 3,38\% solúveis em etanol-benzeno para Pinus elliottii, e 3,48\% para água quente e 3,31\% para etanol-benzeno para Pinus taeda. Estes valores são próximos aos encontrados para este trabalho e mostram que o Pinus elliottii tem quantidade de extrativos um pouco superior ao Pinus taeda.

Para o tempo de estocagem, em ambas as espécies, constatou-se que ocorreu um decréscimo da porcentagem de extrativos solúveis em etanol-tolueno, ao longo do período de armazenamento dos cavacos, concordando com o observado por Brand (2013). 

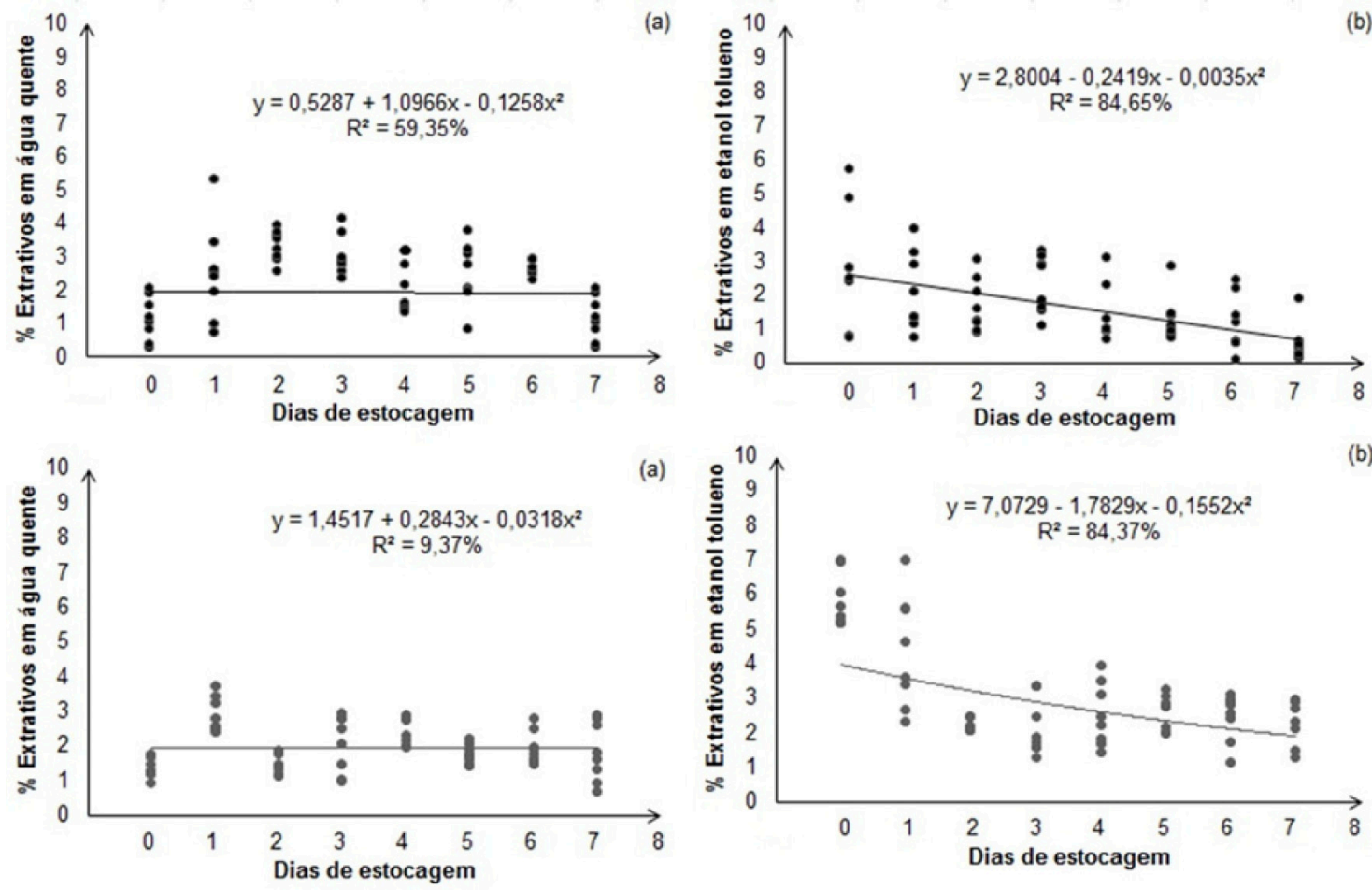

- Pinus tae da

E Pinus elliottii

Figura 4. Variação da quantidade de extrativos solubilizados em água quente (A) e etanol-tolueno (B) em pilhas de cavacos de Pinus taeda e de Pinus elliottii, em função do tempo de estocagem.

Figure 4. Variation of the amount of extractives solubilized in hot water (A) toluene and ethanol (B) in piles of chips of Pinus taeda and Pinus elliottii, depending on storage time.

Principalmente para Pinus elliottii, ocorreu maior redução de extrativos solúveis em etanol-tolueno nos primeiros 3 dias de estocagem, acompanhado de uma queda menos acentuada nos dias subsequentes, até o sétimo dia. Para Pinus taeda, a redução na quantidade dos extrativos solúveis em etanol-tolueno foi menor e mais gradativa que para Pinus elliottii.

Em relação à solubilidade da madeira em etanol-tolueno, ocorreram diferenças significativas ao longo dos dias, apresentando uma alta correlação $\left(\mathrm{R}^{2}=84,65\right.$ e $\mathrm{R}^{2}=84,37$ para Pinus taeda e Pinus elliottii, respectivamente), como pode ser observado pelo modelo de regressão na Figura 4 (b).

A mistura etanol-tolueno utilizada neste estudo remove a fração dos extrativos constituídos por resinas, óleos, ceras, graxas e compostos insolúveis em éter etílico (SARTO; SANSIGOLO, 2010). Silvério et al. (2008), analisando a variação da solubilidade de extrativo na madeira de Eucalyptus spp., estocada na forma de toras, para a produção de celulose, constatou que ocorre uma diminuição no conteúdo de extrativos com o tempo de armazenamento, de forma mais significativa nos primeiros 60 dias após a colheita. Além disso, os ácidos graxos e esteróis foram as principais classes de compostos responsáveis pela diminuição significativa no conteúdo de extração.

Bittencourt et al. (2006) em estudo onde estocaram cavacos para produção de celulose nas mesmas condições apresentadas neste trabalho, constaram que os extrativos são alterados quimicamente e degradados pela elevação da temperatura das pilhas.

Para a solubilidade em água quente, a espécie de Pinus taeda teve uma correlação significativa com $\mathrm{R}^{2}=59,35$. Portanto, ocorreram alterações das porcentagens de extrativos ao longo dos dias de estocagem. Ao contrário, para Pinus elliottii houve baixa correlação (Figura 4), ou seja, não ocorreram mudanças significativas na quantidade de extrativos solubilizados em água ao longo da estocagem.

\section{CONCLUSÕES}

Ocorreu elevação da temperatura interna das pilhas de cavacos, com aumento até o terceiro dia para Pinus taeda e quarto dia para Pinus elliottii, seguida de redução gradativa até o sétimo dia de estocagem. 
Ampessan et al. - Otimização do tempo de estocagem de cavacos de

Pinus taeda e Pinus elliottii para a produção de celulose e papel

- O período de elevação gradativa da temperatura das pilhas (quarto dia) coincidiu com o período de maior proporção de perda dos extrativos solubilizados em etanol-tolueno.

- Não houve variação significativa dos teores médios de extrativos nas profundidades da pilha de cavacos;

- O perfil de elevação da temperatura e o decréscimo do teor de extrativos solúveis em etanol tolueno, para ambas as espécies, indicam que a partir de cinco dias de estocagem os cavacos já apresentaram perda significativa de extrativos solúveis em etanol-tolueno, melhorando desta forma sua qualidade para a obtenção de polpa celulósica pelo processo Kraft.

\section{REFERÊNCIAS BIBLIOGRÁFICAS}

ABRAF - Anuário Estatístico da ABRAF 2011: ano base 2010. Brasília, 2011. 130 p.

BRACELPA - ASSOCIAÇÃO BRASILEIRA DE CELULOSE E PAPEL. Relatório Estatístico 2014. Disponível em: <http://www.bracelpa.org.br>. Acesso em: 01 out. 2014.

ABNT - ASSOCIAÇÃO BRASILEIRA DE NORMAS TÉCNICAS. NBR 14577: pasta celulósica e madeira determinação do material solúvel em água. Rio de Janeiro, 2000.

ABNT - ASSOCIAÇÃO BRASILEIRA DE NORMAS TÉCNICAS. NBR 14853: Madeira - Determinação do material solúvel em etanol-tolueno e em diclorometano. Rio de Janeiro, 2002.

BARONTINI, M.; SCARFONE, A.; SPINELLI, R.; GALLUCCI, F.; SANTANGELO, E.; ACAMPORA, A.; JIRJIS, R.; CIVITARESE, V.; PARI, L. Storage dynamics and fuel quality of poplar chips. Biomass and Bioenergy, Oxford, v. 62, p. 17-25, 2014.

BITTENCOURT, E.; BRAND, M. A.; OLIVEIRA, J. Controle dos Processos de Estocagem da Madeira para minimização dos Problemas no Índice de Luminosidade do Kraft. 2006. 13 p. Relatório técnico.

BRAND, M. A. Influência da espécie na qualidade da biomassa florestal sob estocagem, para geração de energia. Ambiência, Guarapuava, v. 9, n. 3, p. 461-474, 2013.

FENGEL, D.; WEGENER, G. (Ed.). Wood: chemistry, ultrastructure, reactions. Berlin: Walter de Gruyter, 1983. $626 \mathrm{p}$.

GUTIÉRREZ, A.; DEL RÍO, J. C.; GONZÁLEZ-VILA, F. J.; MARTíN, F. Chemical composition of lipophilic extractives from Eucalyptus globulus labill. wood. Holzforschung, Berlin, v. 53, p. 481-486, 1999.

GUTIÉRREZ, A.; DEL RÍO, J. C.; GONZÁLEZ-VILA, F. J.; MARTÍN, F. Analysis of lipophilic extractives from wood and pitch deposits by solid-phase extraction and gas chromatography. Journal of Chromatography A, v. 823, n. 1, p. $449-455,1998$.

HARDELL, H. L.; NILVEBRANT, N. O. A rapid method to discrimination between free and esterified fatty acids by pyrolytic methylation using tetramethylammonium acetate or hydroxide. Journal of Analytical and Applied Pyrolysis, v. 52, n. 1, p. 1-14, 1999.

JIRJIS, R. Effects of particle size and pile height on storage and fuel quality of comminuted Salix viminalis. Biomass and Bioenergy, Oxford, v. 28, n. 2, p. 193-201, 2005.

MORAIS, S. A. L.; NASCIMENTO, E. A.; MELO, D. C. Análise da madeira de Pinus oocarpa Parte 1 - Estudo dos constituintes macromoleculares e extrativos voláteis. Revista Árvore, Viçosa, v. 29, n. 3, p. 461-470, 2005. 
MUÑIZ, G. I. B. Caracterização e Desenvolvimento de Modelos para Estimar as Propriedades e o Comportamento na Secagem da Madeira de Pinus elliottii Engelm. e Pinus taeda L. 1993. 236 p. Tese (Doutorado em Ciências Florestais no Setor de Ciências Agrárias) - Universidade Federal do Paraná. Curitiba, 1993.

NOLL, M.; NAUMANN, A.; FERRERO, F.; MALOW, M. Exothermic processes in industrial-scale piles of chipped pine-wood are linked to shifts in gamma-, alphaproteobacterial and fungal ascomycete communities. International Biodeterioration \& Biodegradation, v. 64, n. 7, p. 629-637, 2010.

RUPAR, K.; SANATI, M. The release of terpenes during storage of biomass. Biomass and Bioenergy, Birmingham, v. 28, n. 1, p. 29-34. 2005.

SARTO, C.; SANSIGOLO, C. A. Cinética da remoção dos extrativos da madeira de Eucalyptus grandis durante polpação Kraft. Acta Scientiarum Technology, v. 32, n. 3, p. 227-235, 2010.

SCHMIDT, F. L. Observations on spontaneous heating toward combustion of commercial chip piles. Tappi, Atlanta, v. 52, p. 1700-1701, 1969.

SENAI/IPT - Celulose e papel: tecnologia de fabricação da pasta celulósica. São Paulo, 1988. v. 1.

SILVÉRIO, F. O.; BARBOSA, L. C. A.; GOMIDE, J. L.; REIS, F. P.; PILÓ-VELOSO, D. Metodologia de extração e determinação do teor de extrativos em madeiras de eucalipto. Revista Árvore, Viçosa, v. 30, n. 6, p. 1009$1016,2006$.

SILVÉRIO, F. O.; BARBOSA, L. C. A.; MALTHA, C. R.; FIDÊNCIO, P. H.; CRUZ, M. P.; VELOSO, D. P.; MILANEZ, A. F. Effect of storage time on the composition and content of wood extractives in Eucalyptus cultivated in Brazil. Bioresource Technology, Essex, v. 99, n. 11, p. 4878-4886, 2008.

SILVESTRE, A. J. D.; PASCOAL NETO, C.; FREIRE, C. S. R. Componentes lipofílicos da madeira de Eucalyptus globulus: composição e comportamento durante a produção de pasta de papel. O Papel-Aveiro, v. 1, p. 5-16, 2005.

SITHOLE, B. B. Modern methods for the analysis of extractives from wood and pulp: a review. Appita, Melbourne, v. 45, p. 260-264, 1992.

SJÖSTRÖM, E.; ALÉN, R. Analytical Methods in wood chemistry, pulping, and papermaking. New York: Springer, $1998.316 \mathrm{p}$.

SUN, R. C.; TOMKINSON, J. Comparative study of organic solvent and water-soluble lipophilics extractives from whear straw I: yield and chemical composition. Journal of Wood Science, Amsterdam, v. 49, n. 1, p. 47-52, 2003.

Recebido em 19/09/2014

Aceito para publicação em 12/06/2015

Sci. For., Piracicaba, v. 43, n. 108, p. 885-893, dez. 2015 DOI: dx.doi.org/10.18671/scifor.v43n108.13 
